\title{
Arbeidsre-integratie blijft mensenwerk
}

Citation for published version (APA):

de Rijk, A. (2018). Arbeidsre-integratie blijtt mensenwerk. Tijdschrift voor Gezondheidswetenschappen, 96(5), 208-215. https://doi.org/10.1007/s12508-018-0161-y

Document status and date:

Published: 01/01/2018

DOI:

10.1007/s12508-018-0161-y

Document Version:

Publisher's PDF, also known as Version of record

Document license:

Taverne

\section{Please check the document version of this publication:}

- A submitted manuscript is the version of the article upon submission and before peer-review. There can be important differences between the submitted version and the official published version of record.

People interested in the research are advised to contact the author for the final version of the publication, or visit the DOI to the publisher's website.

- The final author version and the galley proof are versions of the publication after peer review.

- The final published version features the final layout of the paper including the volume, issue and page numbers.

Link to publication

\footnotetext{
General rights rights.

- You may freely distribute the URL identifying the publication in the public portal. please follow below link for the End User Agreement:

www.umlib.nl/taverne-license

Take down policy

If you believe that this document breaches copyright please contact us at:

repository@maastrichtuniversity.nl

providing details and we will investigate your claim.
}

Copyright and moral rights for the publications made accessible in the public portal are retained by the authors and/or other copyright owners and it is a condition of accessing publications that users recognise and abide by the legal requirements associated with these

- Users may download and print one copy of any publication from the public portal for the purpose of private study or research.

- You may not further distribute the material or use it for any profit-making activity or commercial gain

If the publication is distributed under the terms of Article $25 \mathrm{fa}$ of the Dutch Copyright Act, indicated by the "Taverne" license above, 


\title{
Sickness Absence of Nurses Working in Residential Elder Care
}

\author{
The Essential Role of Psychosocial Job Resources and Home Demands \\ Velibor Peters, MSc, Angelique E. de Rijk, PhD, Josephine A. Engels, PhD, Inge Houkes, PhD, \\ Jan Joosten, PhD, and Ijmert Kant, PhD
}

\begin{abstract}
Objectives: To elucidate the role and pathways of psychosocial home demands, psychosocial home resources, and psychosocial job resources in relation to sickness absence among nurses working in residential elder care. Methods: Longitudinal (SEM) analyses with bootstrapping with a 1 year follow-up among 365 nurses were performed. Survey data and registered sickness absence data were used. Results: A complete mediation model showed the best fit. More psychosocial job resources $(\beta=-1.50)$ like "work schedule fit with private life" predicted less and more psychosocial home demands $(\beta=0.62)$ predicted more psychosomatic health complaints. The job resources and home demands predicted sickness absence duration and episodes 1-year later mediated through nurses' health. Conclusions: More attention is needed for nurses' work schedule fit with private life and their home demands to potentially reduce health-related sickness absence among nurses working in residential elder care.
\end{abstract}

From the Department of Occupation and Health, Hogeschool van Arnhem en Nijmegen, University of Applied Sciences, Nijmegen (Mr Peters, Dr Engels); Department of Social Medicine, Care and Public Health Research Institute (CAPHRI) (Mr Peters, Dr de Rijk, Dr Houkes); Department of Health, Ethics and Society, Care and Public Health Research Institute (CAPHRI) (Dr Joosten); and Department of Epidemiology, Care and Public Health Research Institute (CAPHRI), Maastricht University, Maastricht (Dr Kant), The Netherlands.

All authors have made substantial contributions to the following:

Velibor Peters: the conception and design of the study, acquisition of data, analysis and interpretation of data, drafting the article revising it critically for important intellectual content.

Angelique E. de Rijk (Angelique.deRijk@maastrichtuniversity.nl): the conception and design of the study, acquisition of data, analysis and interpretation of data, drafting the article or revising it critically for important intellectual content, final approval of the version to be submitted.

Josephine A. Engels (Josephine.Engels@han.nl): the conception and design of the study, drafting the article or revising it critically for important intellectual content, final approval of the version to be submitted.

Inge Houkes (Inge.Houkes@maastrichtuniversity.nl): analysis and interpretation of data, drafting the article or revising it critically for important intellectual content, final approval of the version to be submitted.

Jan Joosten (Jan.joosten@ maastrichtuniversity.nl): analysis and interpretation of data in specific the Categorical Principal Components Analysis (CATPCA) analysis, final approval of the version to be submitted.

Ijmert Kant(Ij.kant@maastrichtuniversity.nl): the conception and design of the study, drafting the article or revising it critically for important intellectual content, final approval of the version to be submitted.

Funding: No funding declared.

We hereby state that the manuscript is original, adhered to the STROBE guideline, not previously published, and not under concurrent consideration elsewhere. We state that all authors meet the criteria for authorship, have approved the final article and that all those entitled to authorship are listed as authors.

Clinical Significance: To prevent psychosomatic health complaints and consequently sickness absence of nurses with shiftwork in residential elder care, it is important to increase the fit between the work schedule and nurses' private life and to decrease psychosocial home demands.

Conflicts of Interests: None declared.

Address correspondence to: Velibor Peters, MSc, Hogeschool van Arnhem en Nijmegen, University of Applied Sciences Team, Health Promotion \& Performance, Heyendaalse weg 141, PO Box 6960, 6503 GL Nijmegen, The Netherlands (Velibor.Peters@han.nl).

Copyright (C) 2018 American College of Occupational and Environmental Medicine

DOI: $10.1097 / J O M .0000000000001393$
Keywords: conservation of resources theory, longitudinal study, mediation analysis, motivation, psychosomatic health complaints, registered sickness absence, structural equation modeling, survey

\section{BACKGROUND}

S ickness absence is an important problem associated with high social and financial costs for employers, employees, and their families. ${ }^{1,2}$ Especially in residential elder care sickness absence rates are high $(6.3 \%)$ and higher than in other healthcare professions (eg, $4.6 \%$ among hospital nurses). ${ }^{3}$ Hence, there is a need for preventive measures to reduce sick leave among nurses. Such measures usually take determinants of sickness absence as a starting point. However, sickness absence is a multifaceted and rather complex phenomenon. ${ }^{4}$ There is vast evidence that work-related and health-related factors predict sickness absence. ${ }^{4-6}$ Research has indicated that work-related factors affect sickness absence via deterioration of mental and physical health, thus a mediation effect. ${ }^{7}$ There is increasing evidence that besides psychosocial work-related factors, psychosocial home-related factors are relevant in predicting sickness absence. ${ }^{6,8,9}$ A psychosocial demanding home situation of nurses can lead to health problems. ${ }^{10-13}$ Possible positive effects of work- and home-related resources are not yet taken into account. Thus, the association between the home situation (both demands and resources) and job resources on the one hand and sickness absence on the other hand remains unclear and this study aims to fill this gap. $6,14,15$

\section{The Potential of Resources}

According to the Conservation of Resources theory $(\mathrm{COR})^{16}$ theory, resources are entities that have intrinsic or instrumental value and can be found in the social contexts, including objects, conditions, personal resources, and energy resources. ${ }^{16}$ The COR theory assumes that there are two ways nurses could react when they encounter stressors in their environment and how those encounters could influence their well-being: a loss spiral and resources generating new resources. People attempt to keep resources ${ }^{16}$ and nurses who experience high levels of stress want to keep or regain their energy by reporting ill. In the absence of stressors, people strive to obtain more resources which increases well-being, ${ }^{10,17}$ known as the gain spiral in the COR theory. When more physical and psychological resources are experienced, nurses can invest further in resources instead of preventing the loss. ${ }^{18-20}$ This process could lead to less sickness absence.

\section{Home Demands}

Nurses with a demanding home situation need to invest more effort in order to arrange and fulfil their responsibilities. According to the COR-theory this could lead to a depletion of resources and eventually result in health problems. For example, in their longitudinal research among white-collar workers, Ten Brummelhuis et $\mathrm{al}^{21}$ found that psychosocial home demands predicted sickness absence duration via health problems and with respect to nursing, demands at home are associated with health problems. ${ }^{11,22}$ This also underlines the importance of assessing the psychosocial home 
demands compared with more simple one-dimensional measures such as the number of (small) children, hours spent on housekeeping, or having a relationship or not. For example, Allebeck and Mastekaasa $^{23}$ in their literature review and other research ${ }^{24,25}$ found no evidence for an association between quantitative measures, such as marital status and (number of) children living at home and sickness absence. A specific characteristic of the Netherlands is that the far majority of women work part-time (working part-time is a legal right). Even though, they experience high home demands and high work-life conflict. ${ }^{26}$ Women in the Netherlands are still expected to take care of children or to provide other care tasks and obligations at home. Time at home is more focused on unpaid work for women who have the feeling of being in function. ${ }^{27}$

\section{Home Resources}

The relationship of work-related resources and well-being motivation, and sickness absence is already well researched. ${ }^{21}$ However more research on how home resources determine negative and/or positive work consequences (eg, higher work engagement, better work performance) among nurses is needed. ${ }^{21-23}$ In line with the second central assumption of the COR theory, it is plausible that the home domain could serve as a resource for nurses. According to this second central assumption obtained resources can create a gain spiral, in which resources can accumulate. ${ }^{16}$ Nurses with, for example, high support from relatives at home or more control over how they use their free time or to allocate home tasks seem better equipped to handle, or to handle the consequences of, stressful circumstances and avoid problematic situations at work. Nurses use emotional support from colleagues and friends to cope with aggression of patients. ${ }^{28}$ They experience more resources, such as physical health and emotional support. ${ }^{10,17}$ Also being part of a family appeared to play a role in the prevention of the development of health problems among nurses. ${ }^{17}$ Furthermore, these home resources have shown to positively influence job performance. ${ }^{19}$ This could allow nurses to invest further in resources instead of to prevent losing them. ${ }^{18-20}$

Social support at home, assisting with home duties, or advice from their partners may help nurses to overcome work problems and consequently increase motivation and performance at work. ${ }^{19}$

\section{Job Resources}

Job resources are expected to be negatively related to sickness absence via higher motivation or lower health problems. ${ }^{7,29}$ Specific work schedule related job resources, for example, work schedule fit with private life, work schedule control, and social support at work are included ${ }^{30-33}$ that have proven to diminish the impact of different work schedules. Although it is not always clearcut if a work or home-related factor is a demand or a resource, ${ }^{29}$ in the present research the fit of the work schedule with private life is considered to be a resource. ${ }^{30}$ Work schedules negatively influence health problems, sickness absence, and job departure, ${ }^{34-36}$ but they might also be valued as a resource by nurses working in residential elder care. In line with the COR-theory, work schedules could be functional in achieving work goals, reduce job demands, or stimulate personal growth and development. Work schedules provide opportunities for nurses to combine work and care and to relieve home demands. ${ }^{30,37}$ Job resources are assumed to predict less sickness absence via better motivation and fewer health complaints. $7,38,39$

\section{Sickness Absence}

Sickness absence is defined as absence from work that is attributed to sickness by the employee and accepted as such by the employer. ${ }^{40}$ Two most common absence measures are absence episodes and duration. ${ }^{4,41,42}$ In general, two different pathways are assumed to influence sickness absence episodes and duration. ${ }^{5,6,43}$ The first pathway is that long-term sickness absence is associated with ill health ${ }^{5,23,39}$ that is framed as "involuntary absence." According to the COR-theory, home demands predict health complaints such as burnout, fatigue, and psychosomatic health complaints and health complaints subsequently predict sickness absence duration. ${ }^{5,6,39}$

The second pathway assumes that frequent short-term sickness absence is associated with work environmental factors and work engagement that is framed as "avoidable absence." 5,39,44 According to the COR theory, positive job characteristics lead to positive outcomes such as work engagement, job satisfaction, ${ }^{45}$ and subsequently these factors lead to less sickness absence episodes. ${ }^{6,21,39}$ Furthermore, sickness absence duration and frequency seem also to be positively related to each other. ${ }^{38,39}$

Studies investigating the effects of home characteristics on health and sickness absence are scarce and show inconsistent findings, ${ }^{34}$ due to various and often too simple measures for home characteristics. ${ }^{19,46,47}$ Job demands are in the present research regarded as a confounder. ${ }^{29,48}$

\section{Hypotheses and Research Model}

A longitudinal design is essential to examine how home demands and job and home resources are related to sickness absence. ${ }^{9,21,35}$ It is hypothesized that (see, Fig. 1), when controlled for job demands:

(1) Home demands positively predict sickness absence episodes and sickness absence duration via more health complaints.

(2) Job and Home resources negatively predict sickness absence duration via fewer health complaints and via better motivation.

\section{METHODS}

\section{Sample and Procedure}

In this longitudinal study self-reported questionnaires were used to measure the independent variables. Registered sickness absence data were used to measure the dependent variables. The participants were nurses ${ }^{47}$ in residential elder care. The two facilities that participated were included because the nurses' work schedules generally reflected nursing work schedules in the Netherlands and provided sickness absence data. Questionnaires were sent to the home addresses of all nursing employees. The participants were asked to return them within 2 weeks. Reminders were sent to all participants 2 and 3 weeks after the initial distribution of the questionnaires. The assessment of the questionnaire, which measured the independent and mediating variables, was in October 2009. The questionnaires contained a code to identify participants the second time and to match the organization sickness absence records. To measure sickness absence duration and episodes, we used the organizations' absenteeism reports from October 2009 until October 2010 as dependent variables. This period was chosen because it was long enough to measure possible changes in individual scores and also to control for seasonal effects. ${ }^{49,50}$

\section{Ethical Considerations}

The study was not submitted to an ethical committee because, according to Dutch law (Wet Medisch-Wetenschappelijk Onderzoek met Mensen/Medical Research Involving Human Subjects Act), surveys only have to be submitted to an ethical committee in a limited number of situations, which do not apply to the present study. The study was approved by the management board of the residential elder care homes involved. The participants were informed by individual letter and an institutional newsletter, they were free to refuse to participate and welcomed to ask questions and express concerns about the study any time. Return of a completed questionnaire was taken to imply consent. Data were stored 


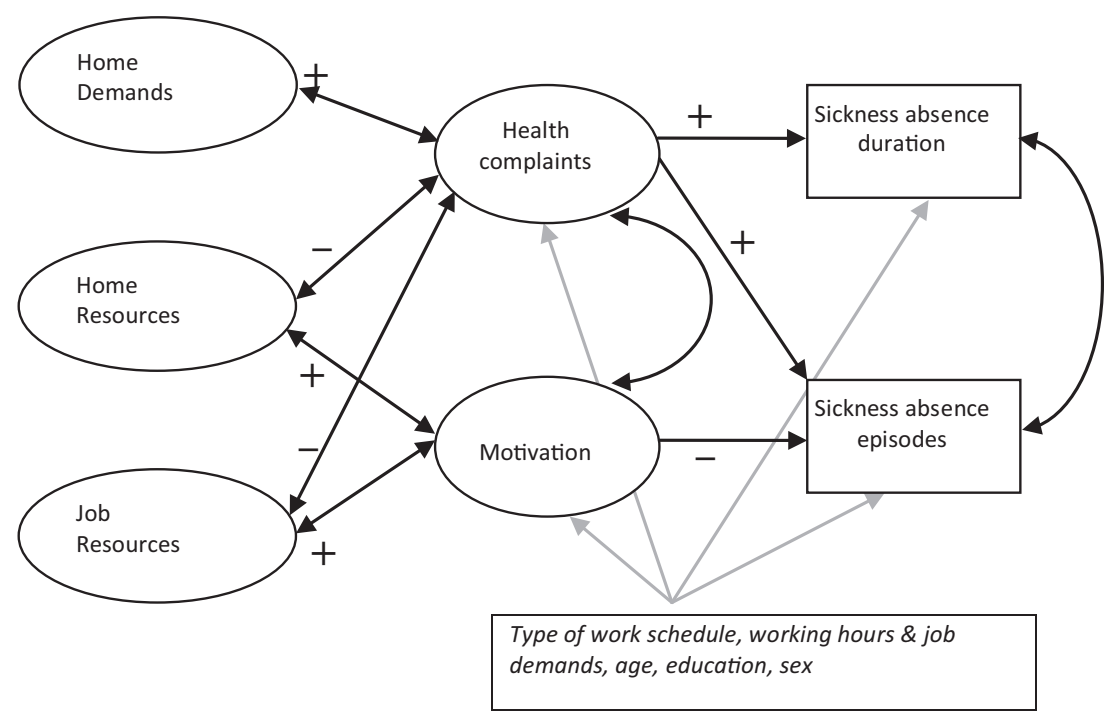

FIGURE 1. The research model.

anonymously, treated confidentially and the participants' privacy was sufficiently guaranteed.

\section{Sample}

The total study population comprised 911 nurses who worked shifts and were employed in one of the two participating residential elder care facilities. The mean age of the research population registered by the organization before the assessment of the questionnaire was 39.8 years ( $\mathrm{SD} \pm 12.3$ ), average working week was 21.5 hours per week ( $\mathrm{SD} \pm 9.8$ ), and median absence duration was 3 days per episode and the median episodes was one time per year. Although "nurse" indicates normally the qualification level of a registered nurse, the current research uses this term for nurses working in residential elder care in the Netherlands. This includes registered nurses, enrolled nurses, licensed vocational or practical nurses, and nurse care helpers. In the Netherlands nurses working in residential elder care are comparable with respect of qualification level to Dutch nurses working in hospitals, home care, care for disabled people and mental health care but do have different psychosocial and physical demands. ${ }^{51}$ At Time 1, 462 questionnaires $(51 \%)$ were included. Only new sickness absence incidents were included. Respondents who left the job, nurses who did not respond, or without sick leave registration were not analyzed.

\section{MEASURES}

\section{Home Demands}

Home demands were operationalized as three psychosocial home characteristics: (1) emotional home demands, (2) quantitative home demands, and (3) cognitive home demands, and measured as follows: emotional home demands contain four, quantitative home demands five, and cognitive home demands four items; they are scored on a 4-point scale ranging from 0 "never" to 3 "always." Example items are: "How often do emotional issues arise at home?", "Do you find that you are busy at home?" and "Do you find that you have to plan and organize a lot of things in relation to your home life?" The internal consistency found (Cronbach $\alpha$ ) is $0.76,0.80$, and 0.80 , respectively. ${ }^{46}$

\section{Home Resources}

Home resources were measured with three psychosocial home characteristics: (1) home autonomy, (2) social support at home, and (3) the possibility to arrange something else. Home autonomy contains four items scored on a five-point response scale, ranging from 0 "never" to 4 "always." An example item is: "I have control over how I use my free time." 19 The internal consistency $\left(\right.$ Cronbach $\alpha$ ) is 0.74 . Social support at home ${ }^{52}$ contains eight items (measuring social support from one's spouse, relatives, and friends) scored on a five-point response scale ranging from 0 "never" to 4 "always." An example item is: "To what extent is/are your [spouse/ relatives/friends] willing to listen to your problems?" The internal consistency (Cronbach $\alpha$ ) is 0.88 . The possibility to arrange someone or something else was measured with a single item: "When something unexpected happens in your home situation, to what extent is it possible for you to arrange things?" This scale uses a 4point response scale that ranges from "never" to "always." 53

\section{Job Resources}

Job resources were measured with three psychosocial job characteristics: (1) work schedule fit with private life, (2) work schedule control, and (3) social support at work. Satisfaction with Irregular Working hours (SIW) ${ }^{10}$ was used to measure the extent to which the work schedule fits with nurses' private life, particularly in relation to leisure time, family situation, social circumstances, sleep, and work-leisure time balance. The scale consists of 14 items that are scored on a five-point response scale ranging from 1 "entirely dissatisfied" to 5 "entirely satisfied," for example: "How satisfied are you with the quality of your contact with family, friends, and spouse given your irregular working hours?" The internal consistency (Cronbach $\alpha$ ) was 0.89. ${ }^{10}$ Work schedule control (WSC) was measured with a scale that assesses perceptions of having choice and influence over starting and ending times, days off, breaks during the workday, swapping shifts, and taking unpaid leave. It consisted of 10 items scored with either 1 ("yes") or 0 ("no"). Example item is: "Can you decide to take a break when you want?" The internal consistency (Cronbach $\alpha$ ) was $0.66 .{ }^{54}$ Social support refers to the worker's perceived social support from supervisors and colleagues. This was measured using a 10-item scale derived from a Dutch questionnaire for organizational stress. ${ }^{55}$ This scale uses a four-point response scale that ranges from 0 "never" to 3 "always" (Item example: "If you have problems at work, can you discuss them with your colleagues?") (Cronbach $\alpha=0.82$ ).

\section{Psychosomatic Health Complaints}

Psychosomatic health complaints were measured with three indicators: (1) emotional exhaustion, (2) general fatigue, and (3) psychosomatic health complaints. Emotional exhaustion was measured using a subscale of the Dutch version of the Maslach Burnout 
Inventory-General Survey. ${ }^{56}$ Emotional exhaustion seems the most characteristic burnout dimension in general and in nursing. ${ }^{57-59}$ The Maslach scale contains five items that are scored on a seven-point response scale ranging from 0 "never" to 6 "always." An example of the items is "Working all day is really a strain for me." The internal consistency (Cronbach $\alpha$ ) is 0.84 to 0.90 . General fatigue was measured with the Multidimensional Fatigue Inventory (MFI). ${ }^{60}$ This scale has four items scored on a five-point scale ranging from "yes, that is true" to "no, that is not true"; a higher score indicates more general fatigue. An example item is "I feel very tired." The internal consistency (Cronbach $\alpha$ ) is 0.84 . Psychosomatic health complaints were measured with a 13-item version of a Dutch perceived health questionnaire (VOEG (Vragenlijst Onderzoek Ervaren Gezondheid [Perceived Health Questionnaire]) developed by Dirken. ${ }^{61}$ The VOEG contains items that ask if the respondent suffers from a range of psychosomatic complaints, such as headaches and backache. Each item is scored with either "yes" or "no." A higher score reflects the presence of more psychosomatic complaints. Internal consistency estimated by Cronbach $\alpha$ is $0.75-0.93$.

\section{Motivation}

Motivation was measured with three indicators: (1) work engagement, (2) job satisfaction, and (3) turnover intention. Work engagement was used to assess positive consequences. It was measured with the short version of the Utrecht Work Engagement Scale (UWES-9). It measures a positive, work-related state of fulfilment that is characterized by vigor, dedication, and absorption. It consists of nine items and has been found to be reliable and valid. ${ }^{62}$ Participants responded on a seven-point Likert scale, ranging from "never" (0) to "always and daily" (6), with higher scores indicating greater work engagement. Examples of items are: "At my work I feel bursting with energy" (vigor), "My job inspires me" (dedication) and "Time flies when I am working" (absorption). The internal consistency (Cronbach $\alpha$ ) is 0.93 . Job satisfaction was measured using a single item asking "How satisfied are you with your job in general?" scored on a 10-point scale ranging from 1 "very dissatisfied" to 10 "very satisfied." Turnover intention was measured by means of a four-item scale originating from the Dutch Quality of Work Questionnaire (Vragenlijst Beleving en Beoordeling van de Arbeid [VBBA] $)^{63}$ ranging from 0 "no" - 1 "yes." An example item is: "I intend to leave this organization this year." The internal consistency (Cronbach $\alpha$ ) is 0.90 .

\section{Sickness Absence Duration and Episodes}

Sickness absence was assessed using the organizations' absenteeism reports. Sickness absence was registered according to the usual Dutch procedures in the Netherlands (number of sick days and duration of absence episodes) and was linked to the data from the questionnaire by a code. To measure the sickness absence duration, the total number of sick days between October 2009 and October 2010 were counted, irrespective of the actual working hours. The sickness absence episodes were assessed as the number of absences between October 2009 and October 2010. The organization registered the reason of absence as reported by the employee. Maternity leave was not categorized as sickness absence, but sick leave during pregnancy in the period not included in the maternity leave was categorized as sickness absence. Absence due to vacation was not included in this measure. Because both measures showed a non-normal distribution, $\log$ transformations were performed. This resulted in reasonable to good normal distributions for sickness absence duration (skewness $=0.798, \mathrm{SE}=0.126$; kurtosis $=-$ $0.533, \mathrm{SE}=0.252$ ) and sickness absence episodes (skewness = $0.339, \mathrm{SE}=0.126$; kurtosis $=-1.076, \mathrm{SE}=0.252$ ) according to Steel. $^{64}$

\section{Confounders}

The type of work schedule ${ }^{47}$ and several work and personal characteristics were taken into account as they may be correlated with health, motivation and sickness absence duration, and episodes $7,29,47,65,66$ and therefore confound the relationships under study. The type of work schedule nurses worked was measured by a new developed typology. ${ }^{67}$ The second work schedule demand was the average number of weekly working hours. The variables were recoded using Categorical Principal Components Analysis (CATPCA) to quantify the type of work schedule and working hours per week with job demands as indicator variables. ${ }^{68}$ Job demands were measured by three dimensions relevant for nurses working in residential elder care: quantitative, emotional, and physical job demands. They were measured with reliable scales originating from the Dutch Quality of Work Questionnaire (Vragenlijst Beleving en Beoordeling van de Arbeid [VBBA]) measuring quantitative job demands, emotional job demands, and physical job demands. ${ }^{63}$ The CATPCA resulted in a five-point scale for the type of work schedule. The quantifications of the type of work schedule and weekly working hours, age, education, and sex have paths to sickness absence duration and episodes, and to health and motivation.

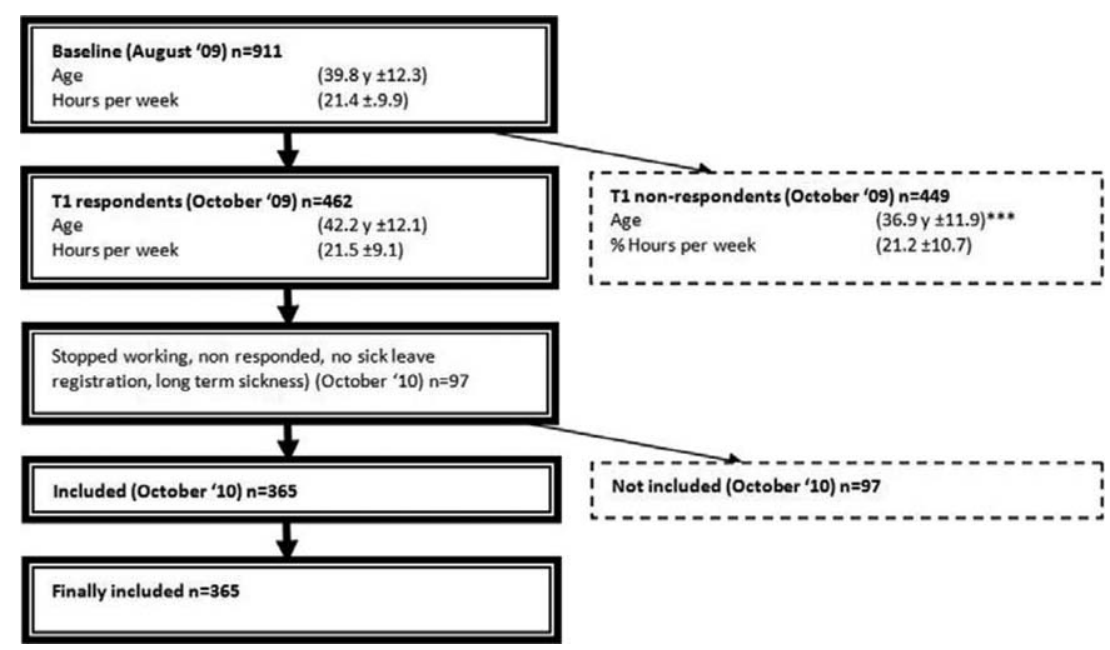

FIGURE 2. Flowchart of inclusion process and $t$ tests between nurses that were included and were not included. 


\section{Analysis}

Structural equation modeling (SEM, IBM SPSS AMOS 20) with maximum likelihood estimation methods were used to answer the research questions, because multinormality was assumed of the endogenous variables in the model. ${ }^{69}$ We used a two-step approach $^{70}$ by first testing the fit of the model's measurement components followed by testing the structural model. The measurement model included five latent variables according to the theoretical model: Home demands, Home resources, Job resources, Health and Motivation.

To test the structural model a nested model approach was used. The model for these analyses included three exogenous latent factors: home resources, home demands and job resources, and two endogenous latent factors: health and motivation. We compared three models: the hypothesized, parsimonious model in which the home demands predicted sickness absence duration and episodes via health and home resources and job resources predicted sickness absence episodes via motivation (M1), the M1 model with paths added linking the home and job resources to health (M2) ${ }^{29}$ and a model testing partial mediation, similar to M2 but with direct paths linking home and job resources and home demands to absence duration and episodes. We tested whether a more parsimonious model fit the data just as well as the research model with more parameters by using a chi-squared difference test. The endogenous latent job resources were allowed to correlate with the latent factors "home demands" and "home resources."

$\mathrm{Chi}^{2}, \mathrm{Chi}^{2}$ difference test, GFI, RMSEA, NFI, and SRMR were assessed. The $\mathrm{Chi}^{2}$, GFI, RMSEA, and SRMR were used to examine the fit of the measurement model to the data. Models with RSMEA below 0.05 in combination with SRMR values below 0.09 indicate excellent fit, whereas values below 0.08 and 0.10 , respectively, are still indicative of a good fit. Models with fit indices of more than 0.95 and an RMSEA of less than 0.06 indicate a close fit between the model and the data. Fit indices between 0.90 and 0.95 represent a reasonable $\mathrm{fit}^{71}$ although Marsh et $\mathrm{al}^{72}$ recommend lower values of cut-off values. In addition, the IFI and the PNFI were used as relative fit indices and to penalize models that are less parsimonious. The error terms of the control variables were allowed to correlate based on the modification indices. In the final model, type of work schedule, average working hours per week, age, education, and sex in line with Olsen and Dahl ${ }^{36}$ were included as control variables.

To test the significance of the regression weights between the predictors, mediators, and sickness absence measures and to test the indirect and total effect bootstrapping was used. Bootstrapping is particular useful when a multiple mediator model is used. It computes more accurate confidence intervals (CIs) of indirect effects that are skewed from zero than the more commonly used methods. ${ }^{73}$ Under conditions of non-normality large samples $(n>200)$ are preferable. ${ }^{74}$ Two thousand new samples were extracted. The null hypothesis, which states that $x$ does not have an indirect effect on $y$ via $m$, is rejected when the entire CI lies above or below zero.

\section{RESULTS}

Organizational databases showed that the nurses in our sample $(n=911)$, were on average 39.8 years old $(\mathrm{SD} \pm 12.3)$ and worked 21.4 hours per week $(\mathrm{SD} \pm 9.9)$ on contractual basis at T0. As can be seen in Fig. 2, 462 responded (51\%) at the first questionnaire assessment (T1, October 2009) that is normal among nurses using mail surveys. ${ }^{75}$ The average age of the respondents (42.2 years; $S D \pm 12.1$ ) according to the organizational databases was higher than $(t$-value $=6.537(889), P<0.001)$ the non-respondents (36.9 years; $\mathrm{SD} \pm 11.9)$. The average working hours per week did not differ between the respondents and non-respondents. Of the 462 nurses that responded to the assessment of the questionnaire (T1, October 2009), 97 were finally excluded because 1 year later

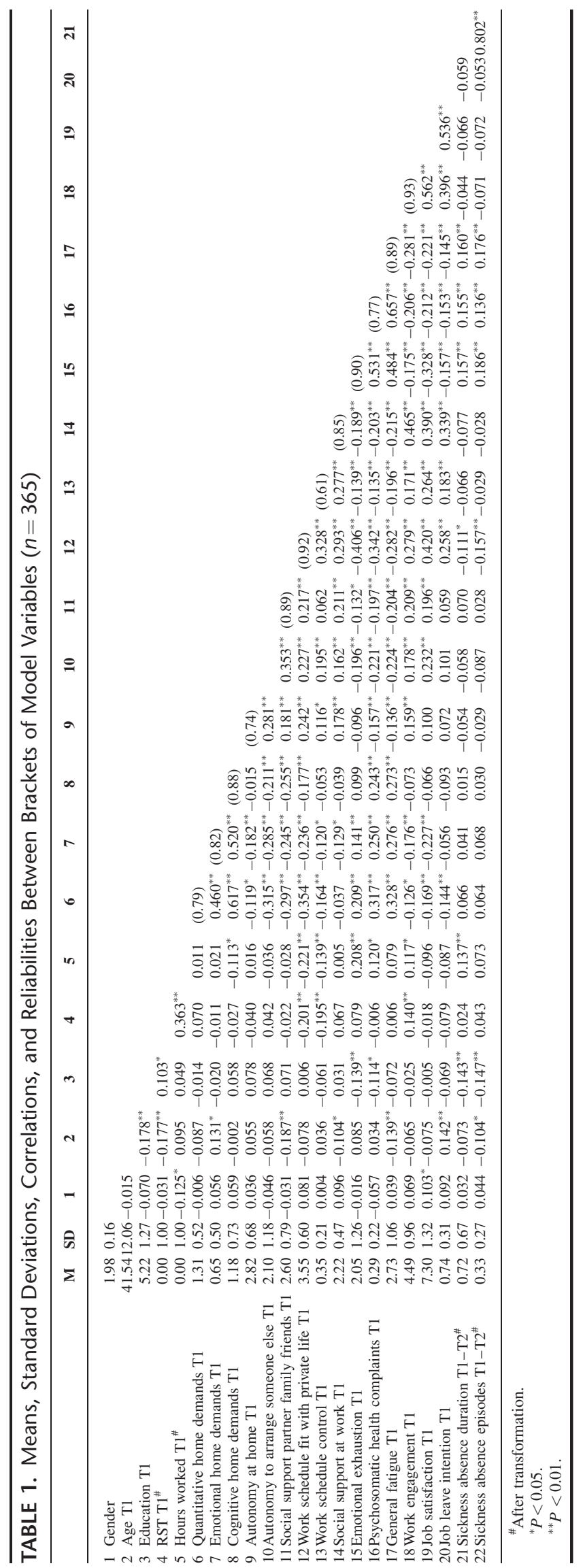


TABLE 2. Results of Structural Equation Modeling

\begin{tabular}{lrrrrrrrrrrr}
\hline Model & \multicolumn{1}{c}{$\chi^{\mathbf{2}}$} & df & RMSEA & $\mathbf{9 0 \%}$ CI RMSEA & SRMR & GFI & AGFI & IFI & PNFI & $\Delta \chi^{2}(\mathbf{d f})$ & $\boldsymbol{P}$ \\
\hline Saturated model & 0.0 & 0 & & & & & 1.000 & & 1.000 & 0.000 & \\
M1 Parsimonious model & 418.8 & 171 & 0.063 & $0.055-0.071$ & 0.0683 & 0.907 & 0.868 & 0.885 & 0.607 & \\
M2 Resources to Health Complaints & 383.7 & 169 & 0.059 & $0.051-0.067$ & 0.0584 & 0.914 & 0.871 & 0.901 & 0.611 & $35.17(2)$ & $<0.001$ \\
M3 Partial mediation & 376.0 & 163 & 0.060 & $0.052-0.068$ & 0.0580 & 0.915 & 0.862 & 0.902 & 0.592 & $7.64(6)$ & $=0.266$ \\
Independent model & 2331.6 & 231 & 0.158 & $0.152-0.164$ & 0.000 & 0.545 & 0.502 & 0.000 & 0.000 &
\end{tabular}

AGFI, adjusted GFI; GFI, goodness-of-fit index; IFI, incremental fit index; PNFI, parsimony normed fit index; RMSEA, root mean square error of approximation; SRMR, standardized root-mean-square residual.

they quit the job, no sickness absence data were available, or were absent due to long-term sickness at baseline.

The final sample $(n=365)$ comprised mainly women (97.6\%), which is normal for residential health care in the Netherlands. The mean age of the respondents was 41.5 years $(\mathrm{SD}=12.1)$. Twenty-two respondents $(6 \%)$ had full-time contracts (36 contractual work hours a week). Sixty-seven percent had children living at home and $33.4 \%$ had children below the age of 12. Correlational analyses showed that these background variables were only marginally related to the model variables (Table 1).

The nurses that finally were included $(n=365)$ were compared with the nurses that were excluded. With respect to the outcome variables, sickness absence duration $(t$-value $=-1.235$ (443), $P>0.05)$ and episodes $(t$-value $=-1.714(443), P>0.05)$ of 2009 did not differ between the respondents and non-respondents. When the sickness absence duration and episodes of our sample between 2008-2009 and 2009-2010 were compared, the mean sickness absence duration was similar $(t$-value $=1.869 \quad(364)$, $P>0.05)$. The number of sickness absence episodes was higher in 2009 compared with 2010 ( $t$-value $=3.667$ (364), $P<0.05)$, Cohen $d=0.211$ which means a small change. ${ }^{76}$ Sex differed slightly between the respondents and non-respondents with somewhat more males that non-responded; $\chi^{2}(1)=5.255, P=0.022$. Hours worked per week $(t$-value $=-2.101$ (456), $P<0.05)$ was higher among the respondents with a Cohen $d=0.244$ which means again a small difference. $^{76}$

\section{Descriptive Statistics}

Table 1 shows the descriptive statistics for each variable measured in the study, the correlation coefficients and the internal consistency of the scale measures.

\section{Results of Structural Equation Modeling}

The measurement model showed a reasonable fit to the data $\left(\chi^{2}(80)=209.17[P<0.001], \mathrm{CFI}=0.92, \mathrm{GFI}=0.93, \mathrm{TLI}=0.89\right.$,
RMSEA $=0.067$ ), with all significant loadings on the intended factors ranging from 0.38 to 0.85 . To test the validity of the measurement model with five factors, we compared it with a one factor model. The fit of the five factor measurement model was better than the fit of a one factor model $\left(\chi^{2}(90)=741.0[P<0.001]\right.$, $\mathrm{CFI}=0.57, \mathrm{GFI}=0.76, \mathrm{TLI}=0.50, \mathrm{RMSEA}=0.141)$.

We compared the model fit with a more parsimonious model with separate pathways and no paths from home and job resources to health complaints (M1) and with a partial mediation model (M3) which included direct effect. Table 2 shows the results of the nested models analyses. Three nested models were compared by means of the chi-squared difference test. The chi-squared difference test showed a worsened fit in the alternative model $\left(\Delta \mathrm{Chi}^{2}(\mathrm{df})=64.1\right.$ (11); $P<0.001)$. This was also confirmed by a higher RMSEA (0.064) and lower GFI (0.90). Also, the alternative model explained a lower amount of variance in sickness absence duration and episodes.

The results of these analyses show that the M1 model fitted reasonable good to the data (see Table 2), but that linking job and home resources to the latent variable "health complaints" improved the chi-squared significantly (M2). Adding direct relationships from the latent exogenous variables home demands, home resources, and job resources to the sickness absence measures (M3) did not significantly improve the chi-square. In addition, the RMSEA was the lowest and (0.059) under the threshold for M2, SRMR was sufficient in combination with the RMSEA. The PNFI was the highest for the M2 model compared with both other models. Therefore, M2, linking home, and job resources to health complaints were considered the best-fitted and most parsimonious model.

The pathway estimates of the final structural model are shown in Fig. 3. Home demands were positively related to health complaints $(\beta=0.62 ;$ LCI-UCI $=0.25-1.05 ; P=0.005)$. Job resources $(\beta=2.22$; $\mathrm{LCI}-\mathrm{UCI}=1.57-3.64 ; P=0.001)$ were positively related to motivation. Job resources were negatively related to

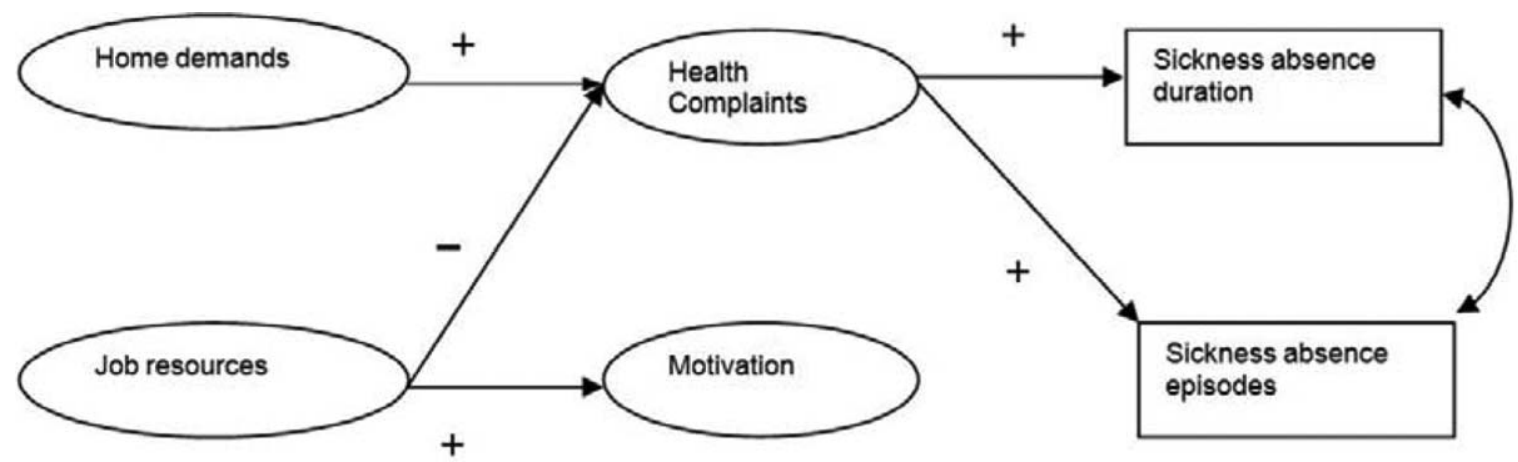

FIGURE 3. The final model (controlled for the type of work schedule, average number of weekly working hours, sex, age, and education). 
TABLE 3. Bootstrapping Results of Indirect and Total Effects of Home Demands and Home and Job on Sickness Absence Duration and Episodes Through Health (m1) and Motivation (m2)

\begin{tabular}{|c|c|c|c|c|c|}
\hline & \multicolumn{2}{|c|}{ Bootstrapping } & \multicolumn{2}{|c|}{ BC $95 \%$ CI } & $\boldsymbol{P}=$ \\
\hline \multicolumn{6}{|l|}{$\mathrm{x} \rightarrow \mathrm{m} 1 \rightarrow \mathrm{y}$} \\
\hline HD $\rightarrow$ health complaints $\rightarrow$ sickness absence episodes & 0.034 & 0.018 & 0.009 & 0.084 & 0.004 \\
\hline $\mathrm{HR} \rightarrow$ health complaints $\rightarrow$ sickness absence duration & 0.017 & 0.080 & -0.067 & 0.214 & 0.665 \\
\hline $\mathrm{HR} \rightarrow$ health complaints $\rightarrow$ sickness absence episodes & 0.000 & 0.016 & -0.027 & 0.039 & 0.986 \\
\hline $\mathrm{HR} \rightarrow$ motivation $\rightarrow$ sickness absence episodes & 0.004 & 0.011 & -0.003 & 0.056 & 0.199 \\
\hline JR $\rightarrow$ motivation $\rightarrow$ sickness absence episodes & -0.050 & 0.042 & -0.148 & 0.021 & 0.139 \\
\hline \multicolumn{6}{|l|}{$\mathrm{x} \rightarrow \mathrm{m} 1, \mathrm{~m} 2 \rightarrow \mathrm{y}$} \\
\hline $\mathrm{HR} \rightarrow$ health complaints, motivation $\rightarrow$ sickness absence episodes & 0.007 & 0.027 & -0.020 & 0.082 & 0.562 \\
\hline $\begin{array}{l}\mathrm{JR} \rightarrow \text { health complaints, motivation } \rightarrow \text { sickness absence episodes } \\
\text { Total effects }\end{array}$ & -0.108 & 0.062 & -0.256 & -0.017 & 0.024 \\
\hline $\mathrm{JR} \rightarrow$ sickness absence episodes & -0.108 & 0.062 & -0.256 & -0.017 & 0.024 \\
\hline
\end{tabular}

BC, two-sided bias-corrected bootstrap confidence interval for the indirect effect; Coeff, unstandardized coefficient; LLCI, lower endpoint of a two-sided bias-corrected bootstrap confidence interval; SE, bootstrap estimate of the standard error; ULCI, upper endpoint of a two-sided bias-corrected bootstrap confidence interval.

health complaints $(\beta=-1.50 ; \quad$ LCI $-\mathrm{UCI}=-2.95$ to -0.71 ; $P=0.001)$. Health complaints were positively related to sickness absence duration $(\beta=0.19 ; \mathrm{LCI}-\mathrm{UCI}=0.09-0.29 ; P=0.001)$ and sickness absence episodes $(\beta=0.06 ;$ LCI-UCI $=0.02-0.09$; $P=0.002$ ). The model explained $9 \%$ of the variance in sickness absence duration and $8 \%$ of the variance in absence frequency.

The results of the indirect and total effects bootstrap results are shown in Table 3.

The results indicated that the indirect relationships between home demands and sickness absence duration and sickness absence episodes were significant. The total effects analysis confirmed these findings. The results indicated that the indirect relationships between job resources and sickness absence duration and sickness absence episodes were significant. The indirect effect on sickness absence episodes via motivation was not significant. The total effects analysis confirmed these findings.

\section{DISCUSSION}

The aim of the current study among nurses working in residential elder care was to gain insight in the role of psychosocial home demands, psychosocial home, and psychosocial job resources with respect to sickness absence duration and episodes, and whether these relationships are mediated by psychosomatic health complaints and motivation. It was hypothesized that home demands would positively predict sickness absence episodes and sickness absence duration via more psychosomatic health complaints, and that job and home resources would predict less sickness absence duration via both fewer psychosomatic health complaints and better motivation.

Using absence data collected during the year following the assessment of independent variables, and controlled for the type of work schedule, working hours, age, education and sex, our study supported hypothesis 1 and merely supported hypotheses 2 . Psychosocial home demands and psychosocial job resources (work schedule fit with private life, work schedule control, and social support from colleagues and supervisors) are predictive for reduction of sickness absence duration and episodes via reduced psychosomatic health complaints but not via increased motivation. Job resources are positively related to motivation. The findings are in support of the health related theories rather than in support of the motivational theories for sickness absence. ${ }^{6}$

With respect to hypothesis 1 , psychosocial home demands have an indirect adverse effect on both sickness absence duration and episodes of nurses via health complaints. These findings are in line with previous research, ${ }^{13,21}$ which showed among mainly white collar workers that home demands lead to sickness absence duration and to absence episodes. Our research shows that these relationships are also applicable to a nursing population working in residential care. This can be explained by the fact that women are still more responsible for household and childcare than men are. ${ }^{27,77}$ Especially nurses with extensive family responsibilities focus more on that, than on their own health and well-being. ${ }^{78}$ An overload of home demands reduces nurses' time to recover from work and could consume their physical and psychological resources..$^{20,79,80}$ This idea is supported by the COR theory that stress and health problems occur when nurses risk losing, or actually lose resources in their home domain consequently leading to sickness absence. ${ }^{16}$

Hypothesis 2, concerning the indirect effect of psychosocial job resources, was partially confirmed. Job resources had an indirect protective effect on sickness absence duration and sickness absence episodes of nurses via health but not motivation. According to the COR theory, ${ }^{16}$ nurses who experience more job resources, are more able to gain resources and are better able to preserve health in demanding situations and consequently prevent prolonged absence from work. Lack of job resources, such as low work schedule fit with private life, low control over work schedules, and less social support of colleagues and supervisors seem especially harmful for a mainly female working population working in emotional demanding jobs. ${ }^{10,81-83}$ The findings imply that, although it is found that the home situation for nurses working in residential elder care facilitate recovery from work, ${ }^{17,79}$ arrangements at the job seems an essential resource to counterbalance the demands at home. 
In contrast with research among managers and executives of a telecom company ${ }^{39}$ and employees of a nutrition production company, ${ }^{38}$ in the present study sickness absence episodes were not related to motivational factors. It seems to imply that findings among other employees are not transferable to the nursing population. This could be due to the fact that nurses can generally be characterized as a highly engaged working population. ${ }^{84,85}$ Additional analysis showed indeed that the nurses in our research were significantly more work engaged than reference scores accompanying the UWES manual ${ }^{86}(t=14.864$ (373); $P<0.001)$ and compared with a group of American nurses ${ }^{87}(t=3.952$ (373); $P<0.001)$. Furthermore, they were significantly more satisfied with their job $(t=11.863$ (373); $P<0.001){ }^{88}$

\section{Limitations and Future Research}

The strengths of this study are its longitudinal design using registered sickness absence data of the following year, the questionnaire includes well-known validated instruments, which also made it possible to consider potential confounding factors, such as work schedule related demands and socio-demographic factors.

Although sickness absence was not verified by a company doctor, the sickness absence data gathered from company records are preferable above sickness absence measured by self-reported questionnaires ${ }^{89}$ which are prone to recall bias. The variance in absenteeism that was explained by health is also higher than in other studies $^{38,39} ; 9 \%$ of sickness absence duration and $8 \%$ of sickness absence episodes.

The robustness of our research model seems sufficient. An alternative model was tested whereby the type of work schedule was fitted into the model as an exogenous variable besides the other exogenous variables home demands, home resources, and job resources. This resulted in the same significant direct and indirect effects. Therefore, the robustness of our research model seems sufficient. Furthermore, our research model showed a better fit than the alternative model. Also, the alternative model explained a lower amount of variance in sickness absence duration and episodes.

Furthermore, the respondents' age, sex, average weekly working hours and number of years in their current jobs were comparable to those of nurses working in comparable facilities in the Netherlands and to several other European countries. ${ }^{3,90}$ However, we controlled for hours working and the type of schedule. Although the far majority of Dutch women work part-time, which slightly differs from other European countries, ${ }^{90}$ they struggle with work-life balance at the same degree as in many other countries. ${ }^{91}$ However, one should be careful with generalizing the results of this study to other countries.

The variables under examination slightly differ between the respondents and non-respondents; the nurses that are included experienced lower work schedule control than the nurses that are not included implying a small effect $(d=0.358) .{ }^{76}$ Nurses included in this study show a small decrease of sickness absence episodes compared with the year before the assessments of the questionnaires. Because of this small effect and because the other variables under study did not differ between the responders and non-responders, it can thus be concluded that selective dropout is not a serious problem in the present study. However, we cannot rule out a healthy worker effect; employees who were unable to do nursing with shiftwork due to various health or motivational problems already stopped working shifts. ${ }^{92}$

Although the model is based on theoretical and empirical grounds, reciprocal relationships could exist. ${ }^{49}$ For example, nurses with health complaints or motivational problems could change to a less demanding work schedule. ${ }^{92,93}$ However, the effect of such a change in shift depends on who initiated the change and if the nurse was forced to. ${ }^{93}$ Consequently, the nurses that are not included possibly could have quit the job or nursing. This could have led to an underestimation of the associations between the home demands, home and job resources and health.

The present findings have implications for future research and practice. The type of work schedule and its fit with private life is valued as a resource by nurses working in residential elder care. The psychosocial approach for example with the ICF-framework seems useful to predict sickness absence. This framework categorizes participation (eg, sickness absence), health and health status of employees and the factors that impact these without valuing determinants on beforehand as a resource or demand. ${ }^{14,15}$

Future research could explore the research model with at least a three wave design making it possible to confirm the causal relationships found in the present study between the home demands and job resources and to test for reciprocal relationships. Our findings have also implications for research models focussing on demands and detrimental effects of shiftwork. Our findings emphasize the importance of including work schedule related job resources and home demands in future shiftwork models. Therefore, it is important to validate our findings to other professions with shiftwork.

Future interventions to prevent sickness absence among nurses working in residential elder care should pinpoint at increasing job resources and lowering home demands. Medical practitioners during consultation or nursing supervisors during performance interviews should discuss nurses' perception of their work schedule fit with private life and their home demands. The SIW-questionnaire for measuring the experienced fit between the nurses' work schedule and their private life could be used as a tool to assist them to monitor work schedule fit on a tailor-made basis. Finally, workplace interventions should periodically monitor health of nurses working in residential elder care more than once a year regarding the dropout in the present study.

\section{CONCLUSION}

This study contributes to the existing knowledge on pathways from the home and job situation to sickness absence duration and episodes. It shows that home demands enhance sickness absence duration and episodes via health complaints and not via a motivational pathway. It also shows that job resources reduce sickness absence via health complaints and not via a motivational pathway. Furthermore, it shows that more job resources enhance motivation of nurses.

\section{REFERENCES}

1. van Amelsvoort LG, Jansen NW, Kant I. Addressing long-term sickness absence: moving beyond disease, illness and work-related factors for effective prevention. Scand J Work Environ Health. 2017;43:1-4.

2. Cooper C, Dewe P. Well-being-bsenteeism, presenteeism, costs and challenges. Occup Med. 2008;58:522-524.

3. Onderzoeksprogramma arbeidsmarkt zorg en welzijn [Research Programm Work in Care and Social Welfare] [database on the Internet]. KIwa Caop; 2015. Available at: http://www.azwinfo.nl/. Accessed October 6, 2016.

4. Davey MM, Cummings G, Newburn-Cook CV, Lo EA. Predictors of nurse absenteeism in hospitals: a systematic review. J Nurs Manag. 2009;17: 312-330.

5. Beemsterboer W, Stewart R, Groothoff J, Nijhuis F. A literature review on sick leave determinants (1984-2004). Int J Occup Med Environ Health. 2009;22:169-179.

6. De Rijk AE. Work disability theories: a taxonomy for researchers. In: Loisel P, Anema H, editors. Handbook of Work Disability. New York, NY: Springer Verlag; 2013.

7. Roelen CA, van Rhenen W, Schaufeli W, et al. Mental and physical healthrelated functioning mediates between psychological job demands and sickness absence among nurses. J Adv Nurs. 2014;70:1780-1792.

8. van Amelsvoort L, de Brouwer CPM, Heerkens YF, Widdershoven GAM, Kant I. Fostering functioning of workers: a new challenge for prevention in occupational health. Work. 2017;57:153-156. 
9. Beauregard N, Marchand A, Blanc ME. What do we know about the nonwork determinants of workers' mental health? A systematic review of longitudinal studies. BMC Public Health. 2011;11:439.

10. Peters V, De Rijk AE, Boumans NP. Nurses' satisfaction with shiftwork and associations with work, home and health characteristics: a survey in the Netherlands. J Adv Nurs. 2009;65:2689-2700.

11. Demir A, Ulusoy M, Ulusoy MF. Investigation of factors influencing burnout levels in the professional and private lives of nurses. Int J Nurs Stud. 2003;40:807-827.

12. Boumans NP, Dorant E. Double-duty caregivers: healthcare professionals juggling employment and informal caregiving. A survey on personal health and work experiences. J Adv Nurs. 2014;70:1604-1615.

13. Voss M, Floderus B, Diderichsen F. How do job characteristics, family situation, domestic work, and lifestyle factors relate to sickness absence? A study based on Sweden Post. J Occup Environ Med. 2004;46:1134-1143.

14. Heerkens YF, Engels J, Kuiper C, Van der Gulden J, Oostendorp R. The use of the ICF to describe work related factors influencing the health of employees. Disabil Rehabil. 2004;26:1060-1066.

15. Kant I, van Amelsvoort L. Applying a biopsychosocial perspective in occupational health: easier said than done! Work. 2017;57:149-151.

16. Hobfoll SE. Social and psychological resources and adaptation. Rev Gen Psychol. 2002;6:307-324.

17. Winwood PC, Winefield AH, Lushington K. Work-related fatigue and recovery: the contribution of age, domestic responsibilities and shiftwork. J Adv Nurs. 2006;56:438-449.

18. Greenhaus JH, Powell GN. When work and family are allies: a theory of work-family enrichment. Acad Manag Rev. 2006;31:72-92.

19. Demerouti E, Bakker AB, Voydanoff P. Does home life interfere with or facilitate job performance? Eur J Work Organiz Psychol. 2010;19:128-149.

20. Ten Brummelhuis LL, Bakker AB. A resource perspective on the work-home interface: the work-home resources model. Am Psychol. 2012;67:545-556.

21. Ten Brummelhuis LL, ter Hoeven CL, de Jong MDT, Peper B. Exploring the linkage between the home domain and absence from work: health, motivation, or both? J Organ Behav. 2013;34:273-290.

22. Pisarski A, Bohle P, Callan VJ. Effects of coping strategies, social support and work-nonwork conflict on shift worker's health. Scand J Work Environ Health. 1998;24:141-145.

23. Allebeck P, Mastekaasa A. Swedish Council on Technology Assessment in Health Care (SBU). Chapter 5. Risk factors for sick leave - general studies. Scand J Public Health Suppl. 2004;63:49-108.

24. Roelen CA, Heymans MW, Twisk JW, et al. Updating and prospective validation of a prognostic model for high sickness absence. Int Arch Occup Environ Health. 2015;88:113-122.

25. Voss M, Josephson M, Stark S, et al. The influence of household work and of having children on sickness absence among publicly employed women in Sweden. Scand J Public Health. 2008;36:564-572.

26. Jansen NWH, Kant I, Nijhuis FJN, Swaen GMH, Kristensen TS. Impact of worktime arrangements on work-home interference among Dutch employees. Scand J Work Environ Health. 2004;30:139-148.

27. Portegijs W, Cloin M, Roodsaz R, Olsthoorn M. Lekker vrij? Vrije tijd, tijdsdruk en de relatie met de arbeidsduur van vrouwen [A day off? Women's free time, time pressure and working hours]. Den Haag: Sociaal en Cultureel Planbureau; 2016. Report No.: ISBN 9789037707762.

28. Lim J, Bogossian F, Ahern K. Stress and coping in Australian nurses: a systematic review. Int Nurs Rev. 2010;57:22-31.

29. Schaufeli WB, Taris TW. A Critical Review of the Job Demands-Resources Model: Implications for Improving Work and Health; 2014:43-68.

30. Peters V, Houkes I, De Rijk AE, Bohle PL, Engels JA, Nijhuis FJN. Which resources moderate the effects of demanding work schedules on nurses working in residential elder care? A longitudinal study. Int J Nurs Stud. 2016;58:31-46.

31. Nijp HH, Beckers DG, Geurts SA, Tucker P, Kompier MA. Systematic review on the association between employee worktime control and worknon-work balance, health and well-being, and job-related outcomes. Scand J Work Environ Health. 2012;38:299-313.

32. Ala-Mursula L, Vahtera J, Linna A, Pentti J, Kivimäki M. Employee worktime control moderates the effects of job strain and effort-reward imbalance on sickness absence: the 10-town study. J Epidemiol Community Health. 2005;59:851-857.

33. Schmieder RA, Smith CS. Moderating effects of social support in shiftworking and non-shiftworking nurses. Work Stress. 1996;10:128-140.

34. Demerouti E, Geurts SA, Bakker AB, Euwema M. The impact of shiftwork on work-home conflict, job attitudes and health. Ergonomics. 2004;47: 987-1002.
35. Merkus SL, van Drongelen A, Holte KA, et al. The association between shift work and sick leave: a systematic review. Occup Environ Med. 2012;69:701-712.

36. Olsen KM, Dahl SA. Working time: implications for sickness absence and the work-family balance. Int J Soc Welfare. 2010;19:45-53.

37. Ruggiero JS, Pezzino JM. Nurses' perceptions of the advantages and disadvantages of their shift and work schedules. J Nurs Adm. 2006;36:450-453.

38. Bakker AB, Demerouti E, de Boer E, Schaufeli WB. Job demands and job resources as predictors of absence duration and frequency. $J$ Vocat Behav. 2003;62:341-356.

39. Schaufeli WB, Bakker AB, Van Rhenen W. How changes in job demands and resources predict burnout, work engagement, and sickness absenteeism. J Organiz Behav. 2009;30:893-917.

40. Whitaker SC. The management of sickness absence. Occup Environ Med. 2001;58:420-424.

41. Hensing G. Swedish Council on Technology Assessment in Health Care (SBU). Chapter 4. Methodological aspects in sickness-absence research. Scand J Public Health Suppl. 2004;63:44-48.

42. Hensing G. The measurements of sickness absence - a theoretical perspective. Norsk Epidemiologi. 2009;19:147-151.

43. Stapelfeldt CM, Jensen C, Andersen NT, Fleten N, Nielsen CV. Validation of sick leave measures: self-reported sick leave and sickness benefit data from a Danish national register compared to multiple workplace-registered sick leave spells in a Danish municipality. BMC Public Health. 2012;12:661672.

44. Kremer AM, Steenbeek R. Avoidable sickness absence in a Dutch working population. J Occup Rehabil. 2010;20:81-89.

45. van der Giezen AM, Bouter LM, Nijhuis FJN. Prediction of return-to-work of low back pain patients sicklisted for 3-4 months. Pain. 2000;87:285-294.

46. Peeters MCW, Montgomery AJ, Bakker AB, Schaufeli WB. Balancing work and home: how job and home demands are related to burnout. Int J Stress Manag. 2005;12:43-61.

47. Peters V, Engels JA, De Rijk AE, Nijhuis FJ. Sustainable employability in shiftwork: related to types of work schedule rather than age. Int Arch Occup Environ Health. 2015;88:881-893.

48. Bakker AB, Demerouti E. The job demands-resources model: state of the art. J Manag Psychol. 2007;22:309-328.

49. De Lange AH, Taris TW, Kompier MAJ, Houtman ILD, Bongers PM. The relationships between work characteristics and mental health: examining normal, reversed and reciprocal relationships in a 4-wave study. Work Stress. 2004; 18:149-166.

50. Zapf D, Dormann C, Frese M. Longitudinal studies in organizational stress research: a review of the literature with reference to methodological issues. $J$ Occup Health Psychol. 1996;1:145-169.

51. Simon M, Tackenberg P, Nienhaus A, et al. Back or neck-pain-related disability of nursing staff in hospitals, nursing homes and home care in seven countries-results from the European NEXT-Study. Int J Nurs Stud [Comparative Study Research Support Non-US Gov't]. 2008;45:24-34.

52. Van Daalen G, Willemsen TM, Sanders K. Reducing work-family conflict through different sources of social support. J Vocat Behav. 2006;69:462-476.

53. Geurts SAE, Taris TW, Kompier MAJ, Dikkers JSE, Van Hooff MLM, Kinnunen UM. Work-home interaction from a work psychological perspective: development and validation of a new questionnaire, the SWING. Work Stress. 2005;19:319-339.

54. Peters V, de Rijk AE, Engels J, Heerkens Y, Nijhuis FJN. A new typology of work schedules: evidence from a cross-sectional study among nurses. Work. 2016;54:21-33

55. Bergers GPA, Marcelissen FHG, De Wolff CJ. VOS-D Test Manual. Nijmegen: Katholieke Universiteit Nijmegen; 1986

56. Schaufeli WB, Van Dierendonck D. Test Manual UBOS. Lisse: Swets Test Services; 2000 .

57. Goodman EA, Boss RW. The phase model of burnout and employee turnover. J Health Hum Serv Adm. 2002;25:33-47.

58. Tourigny L, Baba VV, Han J, Wang X. Emotional exhaustion and job performance: the mediating role of organizational commitment. Int J Hum Resourc Manag. 2013;24:514-532.

59. Wright TA, Cropanzano R. Emotional exhaustion as a predictor of job performance and voluntary turnover, Journal of. Appl Psychol. 1998;83:486-493.

60. Smets EMA, Garssen B, Bonke B, De Haes JCJM. The multidimensional Fatigue Inventory (MFI) psychometric qualities of an instrument to assess fatigue. J Psychosom Res. 1995;39:315-325.

61. Dirken JM. Arbeid en stress [Work and Stress]. Groningen: Wolters Noordhof; 1969. 
62. Schaufeli WB, Bakker AB, Salanova M. The measurement of work engagement with a short questionnaire. Educ Psychol Measur. 2006;66:701-716.

63. Van Veldhoven M, Meijman T. Questionnaire on the experience and evaluation of work. Amsterdam: NIA; 1994.

64. Steel RP. Methodological and operational issues in the construction of absence variables. Hum Resour Manag Rev. 2003;13:243-251.

65. Härmä M. Workhours in relation to work stress, recovery and health. Scand $J$ Work Environ Health. 2006;32:502-514.

66. Michie S, Williams S. Reducing work related psychological ill health and sickness absence: a systematic literature review. Occup Environ Med. 2003;60:3-9.

67. Peters V, De Rijk AE, Engels J, Heerkens Y, Nijhuis F. A new typology of work schedules: evidence from a cross-sectional study among nurses working in residential elder care. Work. 2016;54:21-33.

68. Rodwell J, Fernando J. Managing work across shifts: not all shifts are equal. $J$ Nurs Scholarsh. 2016;48:397-405.

69. Arbuckle JL. IBM SPSS Amos 20 User's Guide. Crawfordville, FL: Amos Development Corporation; 2011.

70. Anderson JC, Gerbing DW. Structural equation modeling in practice: a review and recommended two-step approach. Psychol Bull. 1988;103:12.

71. $\mathrm{Hu} \mathrm{Lt}$, Bentler PM. Cutoff criteria for fit indexes in covariance structure analysis: conventional criteria versus new alternatives. Struct Equat Model. 1999;6:1-55.

72. Marsh HW, Hau KT, Wen Z. In search of Golden Rules: comment on hypothesis-testing approaches to setting cutoff values for fit indexes and dangers in overgeneralizing Hu and Bentler's (1999) findings. Struct Equat Model. 2004;11:320-341.

73. Preacher KJ, Hayes AF. Asymptotic and resampling strategies for assessing and comparing indirect effects in multiple mediator models. Behav Res Methods. 2008;40:879-891.

74. Nevitt J, Hancock GR. Performance of bootstrapping approaches to model test statistics and parameter standard error estimation in structural equation modeling. Struct Equat Model. 2001;8:353-377.

75. Cook JV, Dickinson HO, Eccles MP. Response rates in postal surveys of healthcare professionals between 1996 and 2005: an observational study. BMC Health Serv Res. 2009;9:160.

76. Cohen J. A power primer. Psychol Bull. 1992;112:155-159.

77. Mills M, Taht K. Nonstandard work schedules and partnership quality: quantitative and qualitative findings. J Marriage Fam. 2010;72:860-875.

78. Barthe B, Messing K, Abbas L. Strategies used by women workers to reconcile family responsibilities with atypical work schedules in the service sector. Work. 2011;40(suppl):S47-S58.
79. Demerouti E, Bakker AB, Geurts SAE, Taris TW. Daily recovery from workrelated effort during non-work time. In: Current Perspectives on Job-Stress Recovery. Emerald Group Publishing Limited; 2009. 85-123.

80. Garde AH, Hansen AM, Hansen J. Sleep length and quality, sleepiness and urinary melatonin among healthy Danish nurses with shift work during work and leisure time. Int Arch Occup Environ Health. 2009; 82:1219-1228.

81. Bekker MH, Rutte CG, van Rijswijk K. Sickness absence: a gender-focused review. Psychol Health Med. 2009;14:405-418.

82. Casini A, Godin I, Clays E, Kittel F. Gender difference in sickness absence from work: a multiple mediation analysis of psychosocial factors. Eur $J$ Public Health. 2013;23:635-642.

83. Ala-Mursula L, Vahtera J, Kouvonen A, et al. Long hours in paid and domestic work and subsequent sickness absence: does control over daily working hours matter? Occup Environ Med. 2006;63:608-616.

84. Vinje HF, Mittelmark MB. Job engagement's paradoxical role in nurse burnout. Nurs Health Sci. 2007;9:107-111.

85. Simpson MR. Engagement at work: a review of the literature. Int J Nurs Stud. 2009;46:1012-1024.

86. Schaufeli WB, Bakker AB. Preliminary Manual UWES; Utrecht Work Engagement Scale. Utrecht University: Occupational Health Psychology Unit; 2004.

87. Simpson MR. Predictors of work engagement among medical-surgical registered nurses. West J Nurs Res. 2009;31:44-65.

88. Koopmans L, Bernaards CM, Hildebrandt VH, de Vet HC, van der Beek AJ. Construct validity of the individual work performance questionnaire. J Occup Environ Med. 2014;56:331-337.

89. Van Poppel MNM, de Vet HCW, Koes BW, Smid T, Bouter LM. Measuring sick leave: a comparison of self-reported data on sick leave and data from company records. Occup Med. 2002;52:485-490.

90. Griffiths P, Dall'Ora C, Simon M, et al. Nurses' shift length and overtime working in 12 European countries: the association with perceived quality of care and patient safety. Med Care. 2014;52:975-981.

91. Eurofound. Sixth European Working Conditions Survey-Overview Report. Publications Office of the European Union Luxembourg; 2016.

92. De Raeve L, Kant I, Jansen NW, Vasse RM, van den Brandt PA. Changes in mental health as a predictor of changes in working time arrangements and occupational mobility: results from a prospective cohort study. J Psychosom Res. 2009;66:137-145.

93. Galatsch M, Li J, Derycke H, Muller BH, Hasselhorn HM. Effects of requested, forced and denied shift schedule change on work ability and health of nurses in Europe -Results from the European NEXT-Study. BMC Public Health. 2013;13:1137. 